\title{
Perlite Application and Performance Comparison to Conventional Additives in Blended Cement
}

\author{
Alena Sicakova \\ Institute of Environmental Engineering \\ Technical University of Kosice \\ Kosice, Slovakia \\ alena.sicakova@tuke.sk
}

\author{
Erika Kardosova \\ Institute of Environmental Engineering \\ Technical University of Kosice \\ Kosice, Slovakia \\ erika.kardosova@tuke.sk
}

\author{
Matej Spak \\ Dpt. of Construction Technology \& \\ Management, Technical University of \\ Kosice, Kosice, Slovakia \\ matej.spak@tuke.sk
}

\begin{abstract}
This study compares the performance of perlite with that of conventional additives in blended cements. The results of the application of Perlite Powder (PP) as a component of blended cements in two different proportions $(30 \%$ and $50 \%)$ are presented and compared with standard additives of fly ash (FA) and Ground Granulated Blast Furnace Slag (GGBFS). Moreover, perlite is tested as a component of ternary cement $(70 \%$ cement, $15 \% P$ and $15 \%$ FA and GGBFS alternatively). Blended cements are tested in terms of flexural strength, compressive strength, bulk density, water absorption, and frost resistance. The results show that although perlite blended cements achieve lower strengths and higher absorptivity compared to conventional additives, they have significant potential for freezing and thawing durability, especially in ternary combination with GGBFS. For practical applications, the intrinsic values of the parameters of the individual binders with perlite (e.g. flexural strength of 4.16.2MPa or compressive strength of 18.8-38.5MPa) are sufficient for many practical applications. Perlite, when suitably combined with other pozzolanic materials, can be a suitable component of blended binders.
\end{abstract}

Keywords-blended cements; perlite; slag; fly ash; compressive strength; water absorption; frost resistance

\section{INTRODUCTION}

Cement is a material consisting not only of ordinary concrete, but also of various types of cement composites. Some by-product materials, including Ground Granulated Blast Furnace Slag (GGBFS), Fly Ash (FA) and silica fume, are used as Supplementary Cementitious Materials (SCMs) in a standard way to produce blended cements. Nowadays, when sustainability principles, including the $\mathrm{CO}_{2}$ footprint, have to be taken into account, other SCMs should be researched. These include raw materials, like micro-powder limestone, metakaolin [1], zeolite [2], rice husk ash [3], tile powder [4], perlite, etc. Each of these materials has to undergo preproduction testing before being used as an SCM in concrete. The technical properties (mechanical, rheology, durability and thermo-insulation) and the economic and environmental parameters of these SCMs must also be assessed [5].

Perlite is a highly siliceous and amorphous hydrated volcanic glass containing crystalline impurities, such as quartz, biotite and alkali feldspars and falls in the category of unaltered volcanic alternatives. Perlite is defined as a hydrated natural rhyolite, which is a glass formed from highly siliceous volcanic lava [2]. Perlite varies from other hydrated volcanic glasses (e.g. obsidian or pumice) due to its high water content (typically ranging from 2-5\%) [7]. Perlite contains $\sim 70-75 \%$ $\mathrm{SiO}_{2}$ and $\sim 12-18 \% \mathrm{Al}_{2} \mathrm{O}_{3}$. Due to its glassy structure and high $\mathrm{SiO}_{2}$ and $\mathrm{Al}_{2} \mathrm{O}_{3}$ contents, perlite can be classified as a pozzolan $[8,9]$. In [9], it is shown that the reaction between the lime, silica and alumina of perlite leads to several hydrates, such as calcium silicate hydrate, hydrated calcium aluminates, and hydrated gehlenite. However, as shown in [10], the nature of Perlite Powder (PP) is crucial: if expanded perlite is a source material, due to its cellular microstructure and high porosity, it cannot be used as an effective pozzolanic SCM "as received". Grinding to a suitable grain size is necessary for achieving pozzolanic character. Then, as the fineness of the powder increases, the pozzolanic activity increases. PP is a natural lowprice and commonly available (depending on the region) pozzolan, with the ability to reduce the hydration heat and control the shrinkage of concrete mixtures. Nevertheless, its influence on the properties of concrete, including reactivity (specifically in the early ages), strength, durability, etc. is always a concern [11]. Perlite has been declared as a satisfactory pozzolan with the ability of reducing $\mathrm{CO}_{2}$ emissions and the overall cost of composites [9]. Although the partial cement replacement with perlite significantly reduces the initial strength of mortars during the period from 7 to 28 days, with higher age, the compressive strength differences between the samples containing PP and cement become lower. Authors in [9] reported that the optimal cement replacement ratio of $\mathrm{PP}$ ranges from $10 \%$ to $20 \%$. In addition, densification of the transfer matrix of mortars and good resistance to carbonation were exhibited. Similar results were presented in [12], where it is stated that the pozzolanic activity of PP is slow in the early age and develops with time, resulting in a decrease of absorbability and porosity and an increase in strength.

The lower compressive strength of perlite mortars, compared with cement mortars, was highlighted in [8]. However, due to pozzolanic reactions, these differences are considered to be removed in later ages. The higher amount of perlite in the cement mortar led to a higher demand for water with the same consistency, longer setting time and lower strength. In contrast, the permeability for chloride and autoclave scattering decrease with an increasing percentage of 
perlite [8]. Somewhat different results are presented in [13], where the authors reported that the main parts of the pozzolanic reaction of PP occur after 28 days, but the effect on compressive strength was expressed as insignificant. According to the authors, replacing a part of ordinary Portland cement with PP leads to an insignificant reduction in the compressive strength of the concrete. This reduction is between $8 \%$ and $12 \%$ for concrete with a $30 \%$ replacement.

This study presents the results of the application of perlite as a component of blended cement in two different proportions (representing CEM II/B and CEM IV/B types of cement), and compares it with standard additives (FA and GGBFS) in the same amounts. Moreover, perlite was tested as a component of ternary cement: CEM I+P+FA and GGBFS alternatively. To see the effect of perlite, the ternary cement of CEM I+FA+GGBFS was also studied. This represents the basic contribution of the paper, since, when testing the performance of PP, it is usually used alone as a partial replacement of cement/clinker. However, blended cements in terms of ternary composition are highlighted at present. This is due to the need to apply different SCMs mainly for environmental reasons, as well as for a lack of standard SCMs in some regions (like GGBFS due to the high demand and therefore difficulties in satisfying supplies, and FA due to the lack of one that meets standard requirements for concrete production). Furthermore, some regions or countries may be rich in natural pozzolans but do not generate substantial amounts of artificial pozzolans [14]. The combinations of SCMs need to be tested and optimized to achieve satisfactory performance. In this paper, PP testing is presented by systematic variants of blended binders. The samples were tested in terms of flexural strength, compressive strength, bulk density, water absorption, and frost resistance of the hardened mortar. This study compares the performance of perlite and conventional additives, with 28 -day values taken as the comparative level.

\section{MATERIALS AND METHODS}

To verify the effect of perlite on the properties of the blended binders, ten binder mixtures were designed in different compositions, including the reference one without any additive. PP was applied as a component of Portland cement (CEM) in three different percentage proportions:

- $\mathrm{CEM} / \mathrm{P}=70 / 30$ : the cement represents the CEM II/B-P type of cement according to EN 197-1 [15]

- $\mathrm{CEM} / \mathrm{P}=50 / 50$ : the cement represents the CEM IV/B type of cement according to EN 197-1 [15]

To compare, the same compositions were tested with the utilization of the standard additives FA and GGBFS.

- Ternary cements $\mathrm{CEM} / \mathrm{P} / \mathrm{FA}$ and $\mathrm{CEM} / \mathrm{P} / \mathrm{GGBFS}=$ $70 / 15 / 15$. To see the effect of perlite, also the ternary cement of CEM I+FA+GGBFS composition was tested. These compositions fall into the CEM II/B-M type of cement.

For testing the properties, standard mortars according to EN 196-1 [16] were prepared.

\section{A. Material Characterization}

The following materials were used. The powder materials are shown in Table I, including the presence of main oxides and grain size characteristics.

- Sand (S): CEN Standard sand according to EN 196-1 [16]

- Cement (C): CEM I 42,5 R (CRH Turna nad Bodvou, Slovakia)

- Mixing water (W): tap water

- Mineral additives (Ad): Ground granulated blast furnace slag (S): US Steel Kosice, Slovakia, Fly ash (F): energy segment of steel making factory, US Steel Kosice, Slovakia, and Perlite $(\mathrm{P})$ : natural, finely ground perlite, Lehotka pod Brehmi, Slovakia

TABLE I. PROPERTIES OF CEMENT, PERLITE, SLAG AND FLY ASH

\begin{tabular}{|c|c|c|c|c|c|c|c|}
\hline & $\mathbf{S i O}_{2}$ & $\mathbf{A l}_{2} \mathbf{O}_{3}$ & $\mathbf{F e}_{2} \mathbf{O}_{3}$ & $\mathbf{C a O}$ & Others & \multicolumn{3}{|c|}{$\mathbf{d}(\mathbf{0 . 5})$} & $\mathbf{d ~ ( 0 . 9 )}$ \\
\cline { 2 - 8 } & \multicolumn{6}{|c|}{$[\mathbf{\%}]$} & \multicolumn{2}{|c|}{$[\boldsymbol{\mu m}]$} \\
\hline CEM I 42.5 R & 20.3 & 4.0 & 3.0 & 64.1 & 8.6 & 26.7 & 67.9 \\
\hline $\mathrm{S}$ & 41.3 & 6.3 & 0.4 & 36.0 & 16.0 & 19.0 & 111.5 \\
\hline $\mathrm{F}$ & 56.4 & 19.9 & 7.3 & 4.4 & 12.0 & 19.1 & 94.8 \\
\hline $\mathrm{P}$ & 53.9 & 9.3 & 1.3 & 1.3 & 34.2 & 33.7 & 78.0 \\
\hline
\end{tabular}

\section{B. Experimental Part}

The tested mixtures are given in Table II. First, the binders were prepared according to the proposed percentage composition by dry mixing. The mortar samples were mixed, moulded, and cured in accordance with EN 196-1 [16]. Each batch for three test specimens consisted of $(450 \pm 2) \mathrm{g}$ of binder, $(1350 \pm 5) \mathrm{g}$ of CEN standard sand and $(225 \pm 1) \mathrm{g}$ of water.

TABLE II. COMPOSITION OF BLENDED BINDERS

\begin{tabular}{|c|c|c|c|c|}
\hline \multirow{2}{*}{ Samples } & \multicolumn{5}{|c|}{ Components [\%] } \\
\cline { 2 - 5 } & CEM I 42.5 R & Slag (S) & Fly ash (FA) & Perlite (P) \\
\hline REF & 100 & - & - & - \\
\hline C70S30 & 70 & 30 & - & - \\
\hline C70F30 & 70 & - & 30 & - \\
\hline C70P30 & 70 & - & - & 30 \\
\hline C50S50 & 50 & 50 & - & - \\
\hline C50F50 & 50 & - & 50 & - \\
\hline C50P50 & 50 & - & - & 50 \\
\hline C70/S15/F15 & 70 & 15 & 15 & - \\
\hline C70/P15/F15 & 70 & - & 15 & 15 \\
\hline C70/P15/S15 & 70 & 15 & - & 15 \\
\hline
\end{tabular}

28-day values were taken as the comparative level of the performance of perlite with conventional additives. After the curing days, the following parameters were tested:

- Flexural and compressive strength according to [16].

- Density according to [17].

- Water absorption according to [18]. The method represents a trivial gravimetric course.

- Two of the tested series that proved to be the most promising (70/30 and 70/15/15) were further tested for frost resistance (25 cycles) according to [19]. The cycles consisted of freezing under $-20^{\circ} \mathrm{C}$ ( $2 \mathrm{~h}$ of temperature drop 
and $2 \mathrm{~h}$ of temperature holding) and defrosting under $+20^{\circ} \mathrm{C}$ ( $0.5 \mathrm{~h}$ of temperature rise and $1.5 \mathrm{~h}$ of temperature holding). One freezing-thawing cycle lasts for $6 \mathrm{~h}$. Frost resistance was expressed as a percentage change in flexural and compressive strength after 25 cycles of freezing and thawing.

\section{RESULTS AND DISCUSSION}

The results are shown in Figures 1-6. The values considered were the means of the three results obtained for each set. Table III shows the percentage changes in properties in comparison with the reference sample (REF). The evaluation of the results is mainly focused on samples with perlite, both against the reference sample and samples with conventional additives of GGBFS and FA.

\section{A. Density}

The density of the samples with perlite was between 1960 and $2080 \mathrm{~kg} \cdot \mathrm{m}^{-3}$. Compared to the REF, the density at the C50P50 ratio decreased the most, by $5.9 \%$. The application of additives in principle reduces density, only a $50 \%$ GGBFS replacement increases slightly the value. The C50S50 sample has a $1.5 \%$ higher density compared to the REF sample.

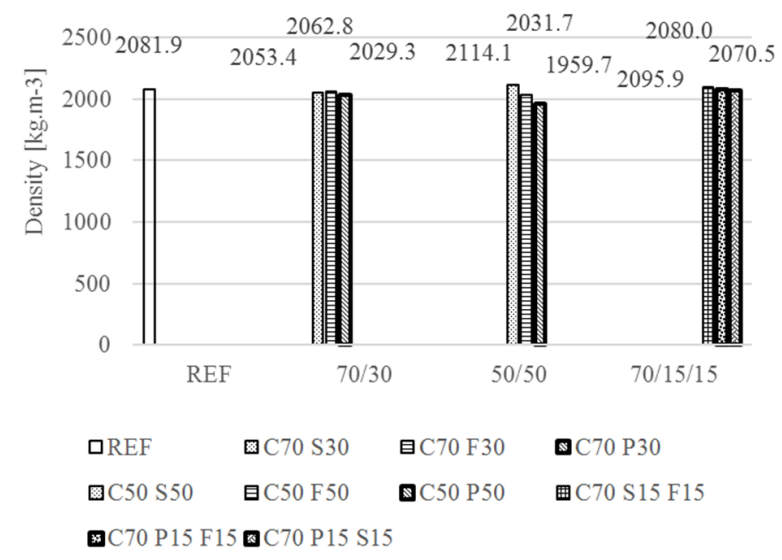

Fig. 1. Density

TABLE III. DIFFERENCES IN PROPERTIES IN COMPARISON WITH THE REFERENCE SAMPLE

\begin{tabular}{|c|c|c|c|c|}
\hline \multirow{2}{*}{ Sample } & Density & $\begin{array}{c}\text { Flexural } \\
\text { strength }\end{array}$ & $\begin{array}{c}\text { Compressive } \\
\text { strength }\end{array}$ & Absorptivity \\
\cline { 2 - 5 } & \multicolumn{4}{|c|}{ Increase / decrease [\%] } \\
\hline C70S30 & -1.4 & -2.9 & -23.9 & 4.9 \\
\hline C70F30 & -1.0 & -15.7 & -28.4 & 6.2 \\
\hline C70P30 & -2.6 & -24.3 & -43.1 & 8.6 \\
\hline C50S50 & 1.5 & -18.6 & -36.0 & 4.9 \\
\hline C50F50 & -2.5 & -28.6 & -50.5 & 13.6 \\
\hline C50P50 & -5.9 & -41.4 & -65.5 & 19.8 \\
\hline C70S15F15 & 0.6 & -2.9 & -18.4 & 7.4 \\
\hline C70P15F15 & -0.1 & -11.4 & -29.4 & 11.1 \\
\hline C70P15S15 & -0.6 & -15.7 & -30.3 & 11.1 \\
\hline
\end{tabular}

Compared to the GGBFS and FA samples, the samples containing $\mathrm{P}$ exhibit a lower density in each of the studied sample groups. Perlite causes a decrease in density by $28.8 \mathrm{~kg} \cdot \mathrm{m}^{-3}$ on average for the $70 / 30$ combination (which represents $\sim 1.4 \%$ of the average density of samples with GGBFS and FA), by $113.2 \mathrm{~kg} \cdot \mathrm{m}^{-3}$ for the $50 / 50$ combination (which represents $\sim 5.5 \%$ of the average density of the GGBFS and FA samples) and by $20.7 \mathrm{~kg} \cdot \mathrm{m}^{-3}$ on average for ternary combinations (which represents $\sim 1.0 \%$ of the density of the GGBFS and FA samples). It can be stated that the use of perlite leads to a negligible decrease in density, either with respect to the reference sample or to the samples with conventional additives.

\section{B. Flexural Strength}

When comparing the effect of additives on flexural strength in the individual sample groups, consistent results were achieved confirming the expectations. The best efficiency (smallest decrease in strength) was caused by GGBFS, followed by FA and finally P. As the amount of additive increases, the strength decreases. All samples where $\mathrm{P}$ was used had reduced flexural strength, not only in comparison with the reference sample, but also with the $\mathrm{S}$ and FA samples. Samples with $\mathrm{P}$ achieved a flexural strength of 4.1-6.2MPa.

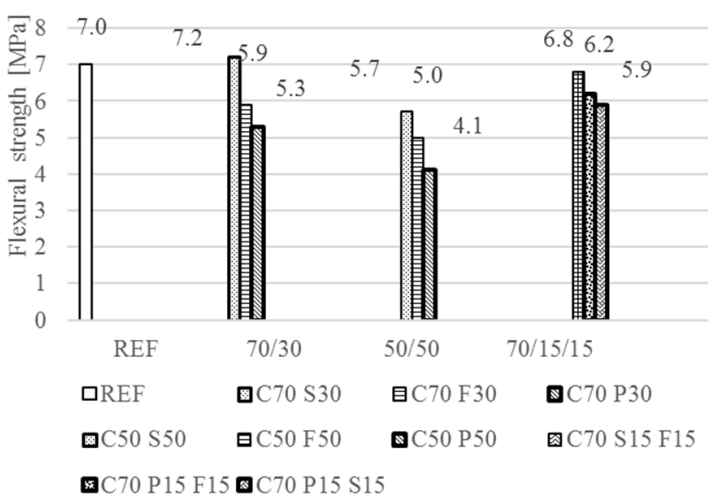

Fig. 2. Flexural strength

Compared to the reference sample, the strength of C50P50 decreased at most by $41.4 \%$. Perlite binders in the ternary combination of C70P15S15 and C70P15F15 had the least decrease in strength of $15.7 \%$ and $11.4 \%$, respectively. Compared to GGBFS and FA samples, perlite causes a greater reduction in the reference flexural strength by $1.3 \mathrm{MPa}$ on average for the 70/30 combination (representing $\sim 20 \%$ of the average GGBFS and FA samples' strength), by 1.3MPa for the $50 / 50$ combination (representing $\sim 25 \%$ of the average strength of the GGBFS and FA samples), and by $0.7 \mathrm{MPa}$ on average for the ternary combinations (representing $\sim 10 \%$ of the strength of the samples with GGBFS and FA). Application of perlite at $30 \%$ of CEM I yields a slightly lower flexural strength than application at $15 \%$ along with GGBFS $(5.3 \mathrm{MPa}$ versus $5.9 \mathrm{MPa})$.

\section{Compressive Strength}

Compressive strength follows the same trend with flexural strength. All samples where perlite was used exhibited reduced compressive strength in comparison with the reference sample and the $\mathrm{S}$ and FA samples. Samples with $\mathrm{P}$ achieved a compressive strength of $18.8-38.5 \mathrm{MPa}$. The results are principally in accordance with [8], where results of $20-30 \%$ 
replacement of cement by perlite were reported. Their 28-day compressive strength went from 34.7 to $42.7 \mathrm{MPa}$.

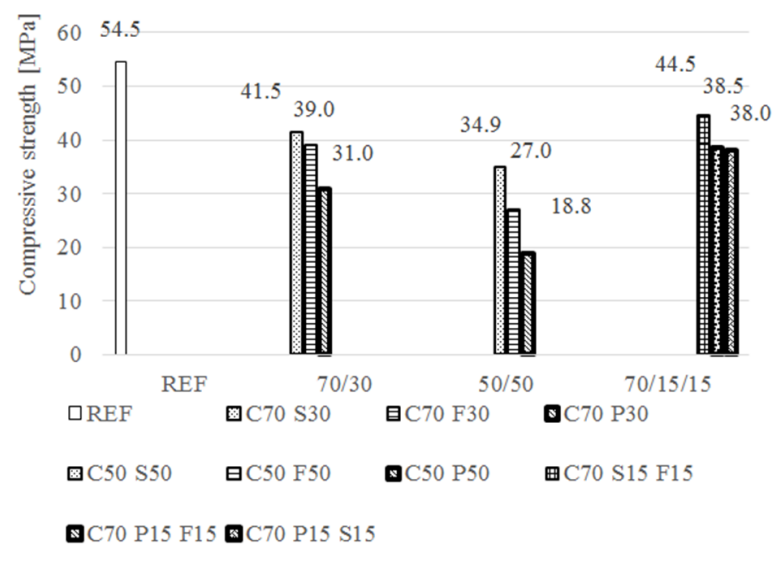

Fig. 3. Compressive strength

Compared with the REF, the strength of C50P50 decreased the most by $65.5 \%$. Binders with perlite in the ternary combinations C70P15S15 and C70P15F15 had the least decreases in strength of $30.3 \%$ and $29.4 \%$ respectively. Compared to slag and FA samples, perlite causes a greater reduction in compressive strength of $9.3 \mathrm{MPa}$ on average in the $70 / 30$ combination (representing $\sim 23 \%$ of the average GGBFS and FA samples strength), by $12 \mathrm{MPa}$ on average for the $50 / 50$ combination (representing $\sim 39 \%$ of the average strength of the GGBFS and FA samples), and by $6.5 \mathrm{MPa}$ on average for ternary combinations (which is $\sim 14 \%$ of the average strength of the GGBFS and FA samples). The application of $30 \%$ perlite yields $7 \mathrm{MPa}$ lower strength than the application of $15 \%$ along with $15 \%$ of GGBFS and FA, respectively (31MPa versus $38 \mathrm{MPa}$, which represents on average one strength class). Looking at the result of C50P50 (18.8MPa), it can be stated similarly to [8] that the higher amount of perlite leads to lower strength. According to [15], the strengths of CEM 32.5 must be between 32.5 and $52.5 \mathrm{MPa}$ at 28 days. Mixtures C70S30, C70F30, C50S50 and all ternary compositions meet this criterion, including both samples with perlite powder C70P15F15 and C70P15S15.

\section{Water Absorptivity}

The absorptivity results correspond (i.e. run in reverse order) to those of the density and strength parameters. With the presence of additives and with an increase in their amount, water absorptivity increases. All samples where perlite was used exhibited increased absorptivity over the reference sample, and the slag and fly ash samples. Samples with perlite achieved an absorptivity of 8.8-9.7\%. Compared to the reference sample, the absorptivity increased to the smallest extent (4.93\%) for samples C70S30 and C50S50. The binder with perlite has the smallest decrease in absorptivity in the C70P30 combination of $8.64 \%$. Compared to the S and FA samples, perlite causes an increase by $0.25 \%$ on average in the $70 / 30$ combination (representing $\sim 2.9 \%$ of the average absorption of GGBFS and FA samples), by $0.85 \%$ for the $50 / 50$ combination (which represents $\sim 9.6 \%$ of the average absorptivity of GGBFS and FA samples) and by $0.3 \%$ on average for ternary combinations (which represents $\sim 3.4 \%$ of the average absorptivity of GGBFS and FA samples). It can be stated that the worse influence of perlite on the absorptivity of mortars compared to slag and FA is negligible in the cases of the 70/30 and ternary combinations. Application of perlite at $30 \%$ of CEM I yields even $0.2 \%$ lower absorptivity than application at $15 \%$ along with $15 \%$ of GGBFS and FA, respectively ( $8.8 \%$ vs. $8.0 \%)$. The results of both strengths are in accordance with the findings in [9], in which a decrease was also observed in the strengths of samples with perlite along with an increase in porosity, which would point to a weaker structure of mortar. As for our results, a weaker structure of perlite specimens is indicated by higher absorptivity, while the results are consistent with strengths: perlite specimens have higher absorptivity with lower strength.

\section{E. Frost Resistance}

The results are shown in Figures 5 and 6. The mean of the three results obtained for each set of three was considered. Table IV shows the percentage changes in properties after 25 cycles of freezing and thawing.

TABLE IV. PERCENTAGE CHANGES IN PROPERTIES IN COMPARISON WITH THE REFERENCE SAMPLE

\begin{tabular}{|c|c|c|}
\hline \multirow{2}{*}{ Sample } & Flexural strength & Compressive strength \\
\cline { 2 - 3 } & \multicolumn{2}{|c|}{ Increase / } \\
\hline decrease [\%]
\end{tabular}

\section{1) Flexural Strength}

A significant decrease in flexural strength after freezingthawing cycles was found for all FA samples, by up to $76 \%$ (C70F30). In contrast, samples with perlite, when used alone or in combination with slag, had only $\sim 5 \%$ lowered strength.

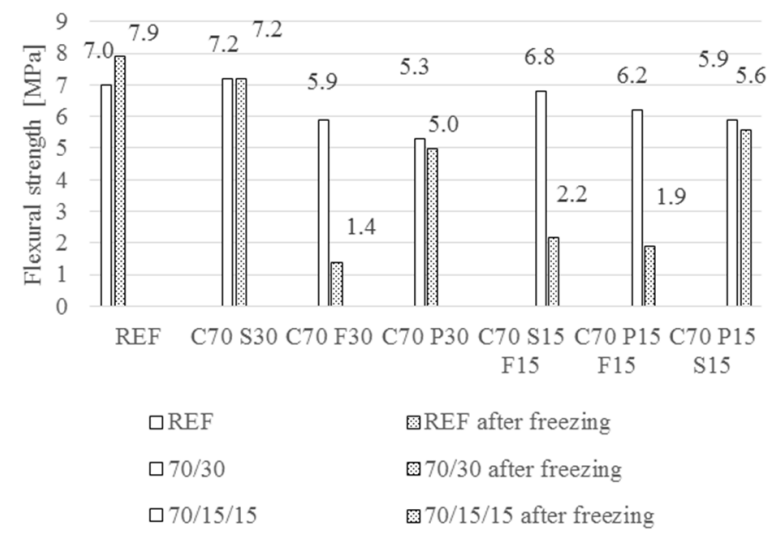

Fig. 4. Frost resistance - flexural strength

With the exception of the reference sample, only three samples achieved good performance in terms of frost resistance limit (minimum $75 \%$ of initial strength): C70S30, C70P30 and C70 P15 S15. 


\section{2) Compressive Strength:}

A significant decrease in compressive strength was found in all samples with FA up to almost $36 \%$ (C70F30). Samples with perlite had a lower strength of only $4 \%$ when combined with slag (C70P15S15) and on a single application the compressive strength after freezing was higher (C70P30). The results are in line with $[20,21]$. In [20], it is stated that samples containing GGBFS achieved better results than the ones containing FA, and the authors in [21] associate the positive effect of GGBFS with its influence on permeability. The good performance of perlite is also in accordance with the results in [22], in which authors showed that frost resistance improved when mixtures were prepared with higher perlite concentration. They suggest that this is partly attributed to the porous nature of perlite that helps reducing the disruptive expansive stresses caused by the freezing-thawing process.

The frost resistance results are consistent. The individual binder compositions are basically in the same order in terms of flexural and compressive strength, as shown in Table V, which is arranged to give a quick indication of the impact of the binder compositions by indicating their order in individual properties, starting from the best. Samples with perlite are highlighted in bold. On the basis of this order, it can be quickly stated that although perlite achieved lower strength compared to conventional additives (GGBFS and FA), it has a promising potential for durability in terms of resistance to freezing and thawing, especially in combination with slag. In contrast, another parameter associated with the characterisation of durability, which is absorptivity, appears relatively unfavourable.

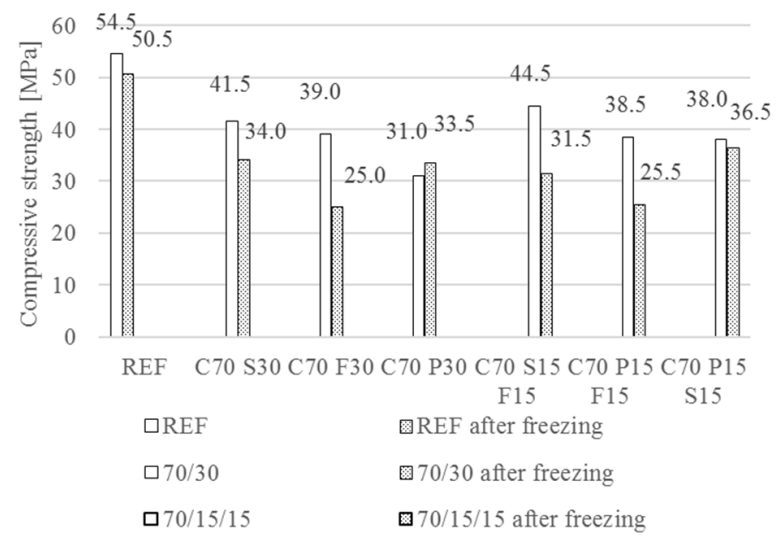

Fig. 5. Frost resistance - compressive strength

TABLE I. SAMPLE PERFORMANCE ORDER IN EACH PROPERTY

\begin{tabular}{|c|c|c|c|c|c|}
\hline \multirow{2}{*}{ Order } & \multirow{2}{*}{ Flexural strength } & \multirow{2}{*}{ Compressive strength } & \multirow{2}{*}{ Absorptivity } & \multicolumn{2}{|c|}{ Frost resistance } \\
\cline { 5 - 6 } & & & Flexural strength & Compressive strength \\
\hline 1 & REF & C70S30 & REF & REF & REF \\
\hline 2 & C70S15F15 & REF & C70S30 - C50S50 & C70S30 & C70P15S15 \\
\hline 3 & C70S30 & C70S15F15 & C70S30-C50S50 & C70P15S15 & C70S30 \\
\hline 4 & C70F30 & C70P15F15 & C70F30 & C70P30 & C70P30 \\
\hline 5 & C70P15F15 & C70F30 & C70S15F15 & C70S15F15 & C70S15F15 \\
\hline 6 & C70P15S15 & C70P15S15 & C70P30 & C70P15F15 & C70P15F15 \\
\hline 7 & C50S50 & C50S50 & C70P15S15 & C70F30 & C70F30 \\
\hline 8 & C70P30 & C70P30 & C70P15F15 & & \\
\hline 9 & C50F50 & C50F50 & C50F50 & & \\
\hline 10 & C50P50 & C50P50 & C50P50 & & \\
\hline
\end{tabular}

\section{CONCLUSION}

The aim of this work was to compare the performance of perlite with the performance of conventional additives (GGBFS and FA), with 28-day concrete properties taken as the comparative level. Ten recipes of binder mixtures have been designed in different compositions, including the reference mixure with no additives. The following percentage ratios of CEM I and additive (Ad) were tested: CEM I/Ad = 70/30, 50/50, and CEM I/Ad1/Ad2 $=70 / 15 / 15$, while all possible combinations of three additives were applied. For testing the properties, standard mortars according to [16] were prepared. After 28 days of curing, the following parameters were tested: density, flexural and compressive strength, and water absorption capacity. Two of the tested series were the most promising (70/30 and 70/15/15) and were further tested for frost resistance.

The use of perlite additive results in a slight decrease in density, in relation to the reference sample or to samples with GGBFS and FA conventional additives. When compared to the average results of samples with GGBFS and FA, the use of perlite causes the following:
- A reduction of flexural strength by $10 \%$ for ternary combinations, by $20 \%$ for $70 / 30$ and by $25 \%$ for the $50 / 50$ combination.

- A reduction of compressive strength of $14 \%$ for ternary combinations, by $23 \%$ for $70 / 30$, and by $39 \%$ for the $50 / 50$ combination.

- An increase in absorptivity by $2.9 \%$ for $70 / 30$, by $3.4 \%$ for ternary combinations, and by $9.6 \%$ for the $50 / 50$ combination.

- Significantly better frost resistance compared to the FA samples.

- Good frost resistance when used alone in 70/30 and when used with GGBFS in $70 / 15 / 15$ as well. The flexural strength decrease after 25 cycles of freezing and thawing was only about $5 \%$, the compressive strength decrease was about $4 \%$ in the $70 / 15 / 15$ combination with GGBFS, and even an increase in strength was observed when used in the $70 / 30$ combination. 
Overall, it can be concluded that although perlite blended binders achieve lower strengths and higher absorptivity compared to conventional additives, they have a promising potential for freezing and thawing durability, especially in ternary combination with slag. From an application point of view however, it should be noted that the values of the individual properties of perlite binders (e.g. flexural strength of $4.1-6.2 \mathrm{MPa}$ or compressive strength of $18.8-38.5 \mathrm{MPa}$ ) are sufficient for a number of practical applications and are expected to meet the required limits. The results are even more promising, as they are 28-day values with the expectation of further improvement in later times, and also because the samples were mortars with fine aggregate, they show a perspective for coarse-grained concrete mixtures.

\section{ACKNOWLEDGMENT}

This research has been carried out within the project of Slovak Scientific Grant Agency VEGA (Grant No. 1/0524/18).

\section{REFERENCES}

[1] A. Saand, M. A. Keerio, D. K. Bangwar, "Effect of Soorh metakaolin on concrete compressive strength and Durability", Engineering, Technology \& Applied Science Research, Vol. 7, No. 6, pp. 2210-2214, 2017

[2] M. M. Ranjbar, R. Madandoust, S. Y. Mousavi, S. Yosefi, "Effects of natural zeolite on the fresh and hardened properties of self-compacted concrete", Construction and Building Materials, Vol. 47, pp. 806-813, 2013

[3] N. Bheel, A. W. Abro, I. A. Shar, A. A. Dayo, S. Shaikh, Z. H. Shaikh, "Use of rice husk ash as cementitious material in concrete", Engineering, Technology \& Applied Science Research, Vol. 9, No. 3, pp. 4209-4212, 2019

[4] N. Bheel, R. A. Abbasi, S. Sohu, S. A. Abbasi, A. W. Abro, Z. H. Shaikh, "Effect of tile powder used as a cementitious material on the mechanical properties of concrete", Engineering, Technology \& Applied Science Research, Vol. 9, No. 5, pp. 4596-4599, 2019

[5] M. Juenger, J. L. Provis, J. Elsen, W. Matthes, R. D. Hooton, J. Duchesne, L. Courard, H. He, F. Michel, R. Snellings, N. De Belie, "Supplementary cementitious materials for concrete: Characterization needs", MRS Online Proceedings Library Archive, Vol. 1488, 2012

[6] M. Rotella, G. Simandl, "Marilla perlite - volcanic glass occurrence, British Columbia, Canada", 37th Annual Forum on Industrial Minerals Proceedings, Industrial Minerals with Emphasis on Western North America, Victoria, Canada, May 23-25, 2001

[7] F. Bektas, L. Turanli, P. J. M. Monteiro, "Use of perlite powder to suppress alkali-silica reaction", Cement \& Concrete Research, Vol. 35, pp. 2014-2017, 2005

[8] T. K. Erdem, C. Meral, M. Tokyay, T. Y. Erdogan, "Effect of ground perlite incorporation on the performance of blended cements", in: Sustainable Construction Materials and Technologies, Taylor and Francis, 2007

[9] F. Guenanou, H. Khelafi, A. Aattache, "Behavior of perlite-based mortars on physicochemical characteristics, mechanical and carbonation: Case of perlite of Hammam Boughrara", Journal of Building Engineering, Vol. 24, Article ID 100734, 2019

[10] L. Kotwica, W. Pichor, W. Nocun-Wczelik, "Study of pozzolanic action of ground waste expanded perlite by means of thermal methods", Journal of Thermal Analysis and Calorimetry, Vol. 123, No. 1, pp. 607613,2016

[11] S. M. M. Karein, A. Joshaghani, A. A. Ramezanianpour, S. Isapour, M. Karakouzian, "Effects of the mechanical milling method on transport properties of self-compacting concrete containing perlite powder as a supplementary cementitious material", Construction and Building Materials, Vol. 172, pp. 677-684, 2018

[12] J. Esfandiari, P. Loghmani, "Effect of perlite powder and silica fume on the compressive strength and microstructural characterization of self- compacting concrete with lime-cement binder", Measurement, Vol. 147, Article ID 106846, 2019

[13] A. A. Ramezanianpour, S. M. M. Karein, A. R. Pilvar, F. Moodi, "Effect of perlite powder on durability properties of concrete under chloride attack", Fourth International Conference on Sustainable Construction Materials and Technologies, Las Vegas, USA, August 7-11, 2016

[14] S. T. Erdogan, A. U Saglik, "Early-age activation of cement pastes and mortars containing ground perlite as a pozzolan", Cement and Concrete Composites, Vol. 38, pp. 29-39, 2013

[15] EN 197-1: Cement. Part 1: Composition, specifications and conformity criteria for common cements, CEN, 2000

[16] EN 196-1: Methods of testing cement. Part 1: Determination of strength, CEN, 2016

[17] EN 1015-10: Methods of test for mortar for masonry. Part 10: Determination of dry bulk density of hardened mortar, SIS, 2000

[18] STN 72 2448: Testing of moisture content and absorptivity of mortar, 1968

[19] STN 73 1322: Determination of frost resistance of concrete, 2016

[20] H. Toutanji, N. Delatte, S. Aggoun, R. Duval, A. Danson, "Effect of supplementary cementitious materials on the compressive strength and durability of short-term cured concrete", Cement and Concrete Research, Vol. 34, No. 2, pp. 311-319, 2004

[21] K. Ebrahimi, M. J. Daiezadeh, M. Zakertabrizi, F. Zahmatkesh, A. H. Korayem, "A review of the impact of micro-and nanoparticles on freezethaw durability of hardened concrete: Mechanism perspective", Construction and Building Materials, Vol. 186, pp. 1105-1113, 2018

[22] A. El Mir, S. G. Nehme, J. J. Assaad, "Durability of self-consolidating concrete containing natural waste perlite powders", Heliyon, Vol. 6, No. 1, Article ID e03165, 2020 